\title{
Human Vitamin D Deficiency in Tibet
}

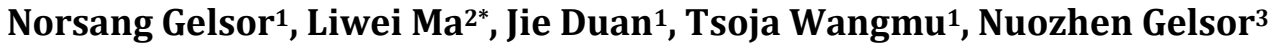 \\ ${ }^{1}$ Geophysics Institute, Tibet University, Tibet, China \\ ${ }^{2}$ Department of Radiation Biology, Institute for Cancer Research, Oslo University Hospital, Oslo, Norway \\ ${ }^{3}$ Department of Physics and Technology, University of Bergen, Bergen, Norway \\ Email: *li-wei.ma@rr-research.no
}

How to cite this paper: Gelsor, N., Ma, L.W., Duan, J., Wangmu, T. and Gelsor, N. (2017) Human Vitamin D Deficiency in Tibet. Food and Nutrition Sciences, 8, 1127-1136.

https://doi.org/10.4236/fns.2017.812084

Received: November 15, 2017

Accepted: December 16, 2017

Published: December 19, 2017

Copyright $\odot 2017$ by authors and Scientific Research Publishing Inc. This work is licensed under the Creative Commons Attribution International License (CC BY 4.0).

http://creativecommons.org/licenses/by/4.0/

\begin{abstract}
Vitamin D contributes significantly to human bone formation, growth, metabolism and disease prevention. During 2007-2009 and 2012-2013, we measured serum calcidiol (25-hydroxyvitamin D3, 25-(OH)D) in Lhasa, Shigatse, Tingri, Nagqu and other places of Tibet in order to get the status of the overall level of vitamin $\mathrm{D}$ in Tibet. We also studied influence of area, occupation, age, gender, season and other factors on the serum 25(OH)D level. Results of our study indicate that: 1) in Tibet, the overall serum concentration of calcidiol is in deficiency range $(25(\mathrm{OH}) \mathrm{D}$ level is $12.25 \mathrm{ng} / \mathrm{ml}) ; 2$ ) the serum level of $25(\mathrm{OH}) \mathrm{D}$ in different regions is generally the same; 3 ) the serum level of $25(\mathrm{OH}) \mathrm{D}$ in young and middle-aged people is $20 \%$ higher than that in elder; 4) the level of $25(\mathrm{OH}) \mathrm{D}$ in male is slightly higher than in female; 5) the level of $25(\mathrm{OH}) \mathrm{D}$ in summer is significantly higher than that in winter; 6) there are obvious differences in serum level of $25(\mathrm{OH}) \mathrm{D}$ among tested subjects with different occupations.
\end{abstract}

\section{Keywords}

Vitamin D, Altitude, Tibet, Solar UV Radiation

\section{Introduction}

Vitamin D plays a very important role for the human health. It has five different forms. The most important ones are vitamin D2 (ergocalciferol) and vitamin D3 (also known as cholecalciferol) [1].

Vitamin D is one of the most crucial regulators for metabolism of calcium and phosphorus [2]. In 1923, Harry Steenbock proved that ultraviolet radiation increased vitamin D content for treatment of human rickets and osteomalacia. Now, vitamin D is the preferable drug for prevention of osteoporosis due to its ability to enhance bone density and strength [3] [4] [5]. 
A number of scientific research results show that vitamin $\mathrm{D}$ can prevent excessive cell proliferation to reduce the risk of cancer [1] [6]. Moreover, Johan Moan et al. found that high vitamin $\mathrm{D}$ level at the time of diagnosis of cancer seemed to give an increased survival rate [7]. Alina Porojnicu et al. reported that vitamin D has a potential prognostic factor in Hodgkin's lymphoma. They raised their standpoint by analysis of the Norway national data from 1964 to 2000. Fatality of patients diagnosed with Hodgkin's lymphoma in the fall was $20 \%$ lower than those who diagnosed with Hodgkin's lymphoma in winter. Furthermore, the improved autumnal survival rate was much higher for patients younger than 30 years [8].

Adequate vitamin D could strengthen immunity [2] [9], prevent and treat heart diseases [5] [10], ensure better development of fetus [11]. Vitamin D could also treat hypertension, diabetes, Alzheimer's disease and other diseases effectively [5] [12]. In recent years, research groups point out that vitamin D can prevent tooth decay [13]; vitamin D deficiency not only makes people feeling of fatigue [14] [15], but also can make people depressed or even cause depression [16]. A large number of studies further point out that many diseases are accompanied by vitamin $\mathrm{D}$ deficiency, and the vitamin $\mathrm{D}$ level can indicate the severity of some certain diseases [17]. Therefore, it is essential to improve the level of vitamin D.

Vitamin D from the diet or dermal synthesis from sunlight is the only two ways in biologically inactive [12] [18], and the latter is the most important way. Tibet has abundant solar energy resources since it lies at a low latitude and at a high altitude. However, because of its high altitude and tough circumstances, the research of vitamin D is developed slowly in Tibet. In 2007, for the first time, Gelsor Norsang et al. carried out the study of vitamin D in Tibet [19]. The results showed that the level of human vitamin D in Tibet was relatively low, and the levels were different in different occupation.

From 2008 to 2013, further study on vitamin D in Tibet was performed continuously. Blood samples were collected from several places in Tibet and the serum calcidiol $(25(\mathrm{OH}) \mathrm{D})$ was measured. The influence of factors such as regions, seasons, occupations on Tibetans vitamin level was studied and analyzed. Suggestions in prevention and treatment of disease by using vitamin $\mathrm{D}$ were given to Tibetans.

\section{Materials and Methods}

During April, June, August, November of 2008 and February, January of 2009, blood samples were taken from 16 persons six times ( 7 males and 9 females. 81 blood samples in total were taken ultimately, because some volunteers could not follow the measurements in the end) in the Nicang village of Shigatse city in Tibet, as illustrated in Table 1. During 2012 and 2013, blood samples were taken from 290 persons lived in different places in Tibet. Males and females of different ages and different occupations were included (blood samples of 
Table 1. Sampling of Vitamin D in Shigatse, Tibet during 2008 and 2009.

\begin{tabular}{|c|c|c|c|c|}
\hline \multirow{2}{*}{ Sampling time } & \multirow{2}{*}{ Simples } & \multicolumn{2}{|c|}{ Gender(n) } & \multirow{2}{*}{ Occupation } \\
\hline & & Male & Female & \\
\hline 2008.04 & 16 & 7 & 9 & \multirow{7}{*}{ Farmers } \\
\hline 2008.06 & 16 & 7 & 9 & \\
\hline 2008.08 & 13 & 6 & 7 & \\
\hline 2008.11 & 10 & 3 & 7 & \\
\hline 2009.01 & 12 & 7 & 5 & \\
\hline 2009.02 & 14 & 8 & 6 & \\
\hline Total & 81 & 38 & 43 & \\
\hline
\end{tabular}

children and adolescents were not taken as not be permitted by residents), as illustrated in Table 2.

The blood sample was centrifuged at $1000 \mathrm{rpm}$ for $15 \mathrm{~min}$ after letting it stand at room temperature for $10 \mathrm{~min}$. Then the serum (upper layer) was transferred to special Eppendorf tube. For each blood sample, at least $50 \mu \mathrm{l}$ serum was extracted for the measurement. The serum samples were frozen and transported to Beijing, where they were analyzed by the Beijing Furui Bio-engineering Company (Haidian District, Beijing, China). A standard radioimmune assay was employed to determine the serum concentrations of $25(\mathrm{OH}) \mathrm{D}$ [19].

\section{Results}

Vitamin D deficiency can lead to a variety of diseases. However, there is no unique criteria of serum levels of $25(\mathrm{OH}) \mathrm{D}$ for human health. In this article, we use the standard set by Osteoporosis Committee of China Gerontological Society (published in 2014, same with the American Institute of Medicine [20]), which defined vitamin D deficiency at serum levels of $25(\mathrm{OH}) \mathrm{D}$ less than $30 \mathrm{nM}$, vitamin D inadequate is at serum levels of $25(\mathrm{OH}) \mathrm{D}$ between 30 and $50 \mathrm{nM}$, vitamin $\mathrm{D}$ adequate is at serum levels of $25(\mathrm{OH}) \mathrm{D}$ greater than $50 \mathrm{nM}$.

The serum 25(OH)D level of blood samples taken from Lhasa and surrounding towns, Nagqu, Tingri, Shigatse (Nicang village and Bianxiong village) during 2012 and 2013 were analyzed (Figure 1). It is clear that the vitamin D level in Tibet is in severely low range. More than 90 percent of residents are in the deficiency range or inadequate range. In 2012, among 162 volunteers in the survey, only 16 volunteers are in adequate range, which accounted for only $9.88 \%$ of the total; 82 volunteers are in inadequate range, which accounted for $50.62 \%$; 64 volunteers are in deficient range accounted for $39.51 \%$ of the total. While, in 2013 more than half of volunteers are in deficiency range.

Tibet is located in the Qinghai Tibet Plateau, with an average altitude of 4000 meters above sea level, varying largely in different regions. We analyzed the levels of serum 25(OH)D in different regions. Figure 2 showed that the average levels of serum $25(\mathrm{OH}) \mathrm{D}$ were all in deficiency range in Lhasa $(12.6 \pm 5.0 \mathrm{ng} / \mathrm{mL})$, 
Table 2. Sampling of Vitamin D in Tibet during 2012 and 2013.

\begin{tabular}{|c|c|c|c|c|c|c|c|c|}
\hline \multirow{3}{*}{$\begin{array}{c}\text { Sampling } \\
\text { Location }\end{array}$} & \multicolumn{4}{|c|}{2012} & \multicolumn{4}{|c|}{2013} \\
\hline & \multirow{2}{*}{ Occupation(n) } & \multicolumn{2}{|c|}{ Gender(n) } & \multirow{2}{*}{ Age(n) } & \multirow{2}{*}{ Occupation(n) } & \multicolumn{2}{|c|}{ Gender(n) } & \multirow{2}{*}{ Age(n) } \\
\hline & & Male & Female & & & Male & Female & \\
\hline \multirow{3}{*}{ Lhasa } & Farmers(29) & & & & Farmers(29) & & & \\
\hline & Teachers(5) & 23 & 28 & $<30(43)$ & Teachers(1) & 14 & 19 & $<30(23)$ \\
\hline & Students(17) & & & $30 \sim<40(26)$ & Students(3) & & & $30 \sim<40(17)$ \\
\hline Shigatse & Farmers(36) & 14 & 22 & $40 \sim<50(32)$ & Farmers $(40)$ & 14 & 26 & $40 \sim<50(33)$ \\
\hline Tingri & Farmers(33) & 7 & 26 & $50 \sim<60(26)$ & Farmers(15) & 8 & 7 & $50 \sim<60(27)$ \\
\hline Nagqu & Herdsmen(42) & 26 & 16 & $\geq 60(35)$ & Herdsmen(40) & 20 & 20 & $\geq 60(28)$ \\
\hline
\end{tabular}

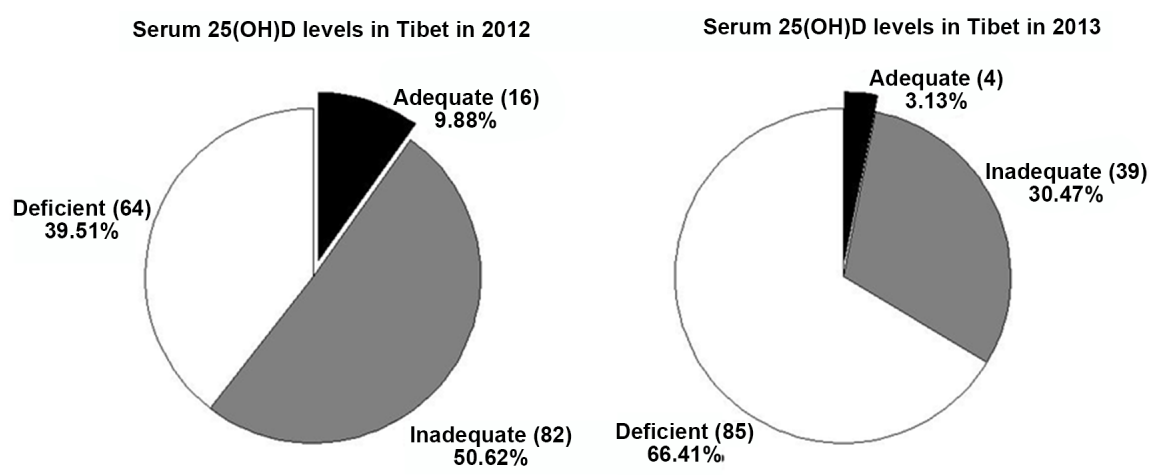

Figure 1. The overall levels of serum 25(OH)D in Tibet during 2012 and 2013.

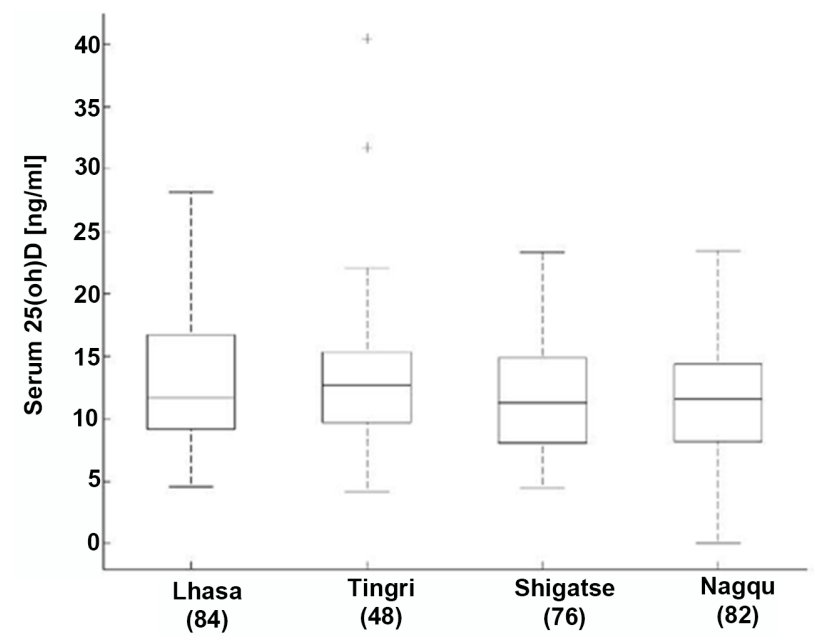

Figure 2. The levels of serum $25(\mathrm{OH}) \mathrm{D}$ in different regions in Tibet during 2012 and 2013.

Nagqu $(11.5 \pm 4.9 \mathrm{ng} / \mathrm{mL})$, Shigatse $(11.9 \pm 4.7 \mathrm{ng} / \mathrm{mL})$ and Tingri $(13.4 \pm 6.5$ $\mathrm{ng} / \mathrm{mL}$ ) during 2012 and 2013. The levels of serum 25(OH)D in Lhasa, Nagqu, Shigatse were even lower than that of Tingri. The most reasonable explanation maybe is that Tingri lies at lower latitudes.

In agreement with our previous article [19], there is a great difference in levels 
of serum 25(OH)D over different time. We found the level of serum 25(OH)D in the blood samples taken from Nicang village of Shigatse City changed during the years of 2007, 2008-2009 and 2012-2013 (the blood sample taken from residents of Bianxiong village where it is not far from Nicang village) (Figure 3).

Figure 3 shows that the levels of serum 25(OH)D in the residents of Nicang village of Shigatse City is declining. It decreased by 50\% from an adequate level $(25.42 \mathrm{ng} / \mathrm{ml})$ to an inadequate level $(12.25 \mathrm{ng} / \mathrm{ml})$ in six years from 2007 to 2013.

A large number of research studies found that the serum 25(OH)D level decreased significantly in winter compared with summer, due to less outdoor activities in winter, which hinder the synthesis of vitamin D. This finding was also evident in our study (Figure 4, the average group is the mean value of the Lhasa, Shigatse, Tingri, Nagqu). Analysis from blood samples taken during 2012 and 2013 showed the serum 25(OH)D levels in winter (from 1st of December to 30th of April, $10.4 \pm 4.5 \mathrm{ng} / \mathrm{mL}$ ) decreased by 25 percent compared with summer (1st of May - 30th of October, $13.8 \pm 5.1 \mathrm{ng} / \mathrm{mL})$ in Tibet $(P<0.001)$. Moreover, the fact is demonstrated again by our research carried out in Nicang village during 2008 and 2009 (data not shown), in which the serum 25(OH)D level in winter decreased by 30 percent compared with summer.

The serum 25(OH)D level varies with ages. Figure 5 showed content of serum $25(\mathrm{OH}) \mathrm{D}$ in all ages (over 18 years old). The serum 25(OH)D level of residents whose ages were between 20 and 40 years old was 20 percent higher than those over 40 years old. We believe this is related to less outdoor activities of middle-aged and older people.

We have tested the 25(OH)D level in different gender. The data of Figure 6 (the average group is the mean value of the Lhasa, Shigatse, Tingri, Nagqu) demonstrated that in addition to Tingri, the level of serum 25(OH)D for male $(12.8 \pm 4.9 \mathrm{ng} / \mathrm{mL})$ was higher than for female $(11.9 \pm 5.3 \mathrm{ng} / \mathrm{mL}, P>0.05)$.

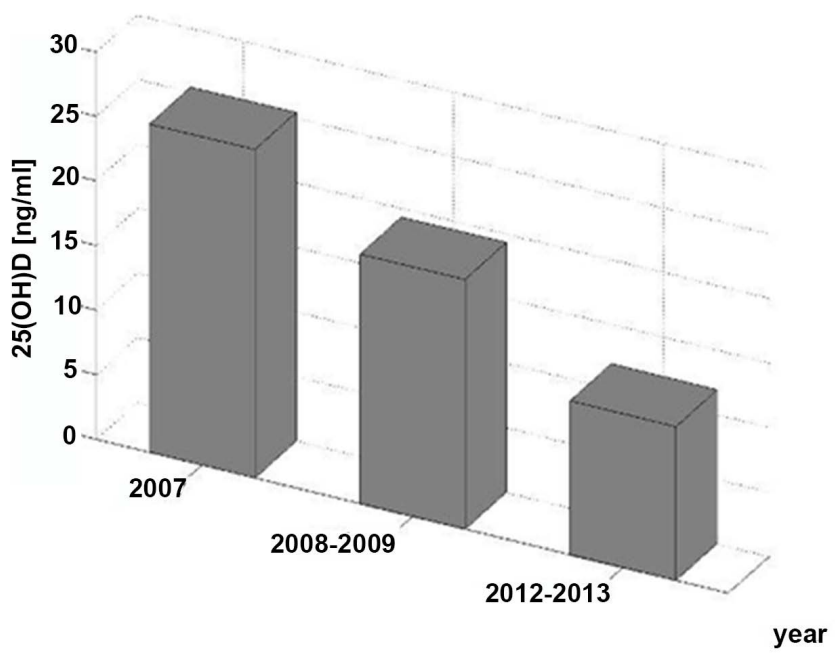

Figure 3. The levels of serum $25(\mathrm{OH}) \mathrm{D}$, in different years, of the residents of Nicang village of Shigatse City, Tibet. 


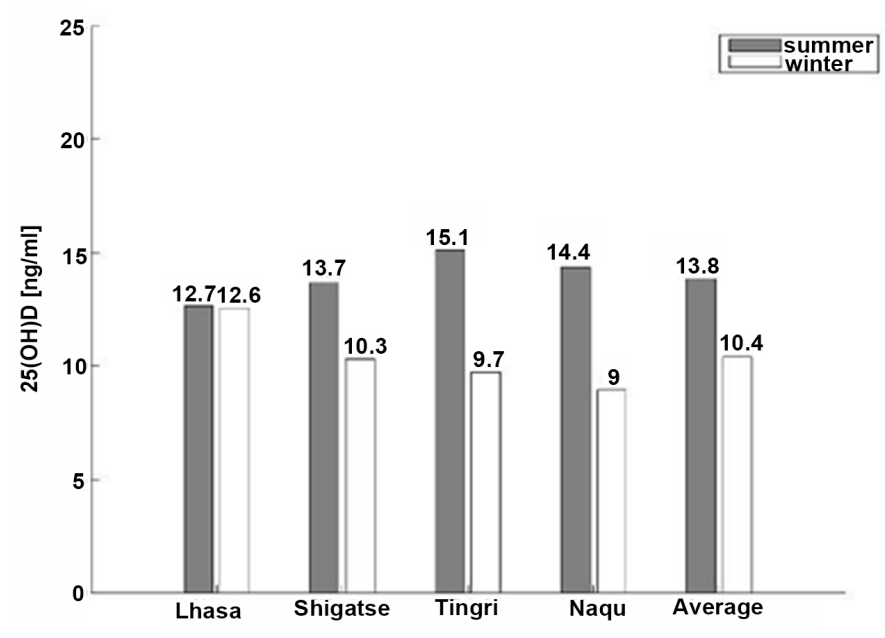

Figure 4. The serum $25(\mathrm{OH}) \mathrm{D}$ level in summer and winter in Tibet during 2008-2009.

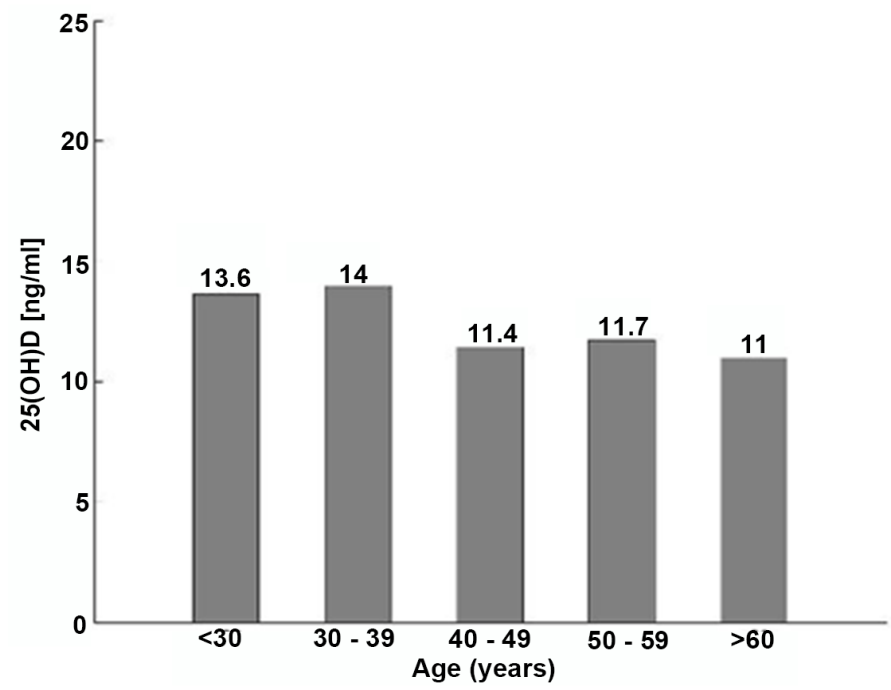

Figure 5. The serum $25(\mathrm{OH}) \mathrm{D}$ level in different ages in Tibet during 2012-2013.

We noticed most male volunteers in Tingri were over 50 years old when took blood examples, which perhaps is the reason for the unexpected data in Tingri.

Figure 7 showed the serum 25(OH)D level of people of different occupation in Lhasa and surrounding towns during 2012 and 2013. We found that the serum 25(OH)D level of all occupation were in deficiency range. Students and teachers serum $25(\mathrm{OH}) \mathrm{D}$ level $(14.7 \pm 4.9 \mathrm{ng} / \mathrm{mL})$ is bit higher than farmers $(11.1 \pm 4.7 \mathrm{ng} / \mathrm{mL})$ and herdsmen $(14.4 \pm 3.9 \mathrm{ng} / \mathrm{mL})$.

\section{Discussion}

Around $90 \%$ of human Vitamin D synthesis is due to exposure of skin to sunlight, specifically to UV radiation. There is abundant solar UV available in Tibet. Ultraviolet intensity is up to level 5 , the maximum ultraviolet radiation intensity 


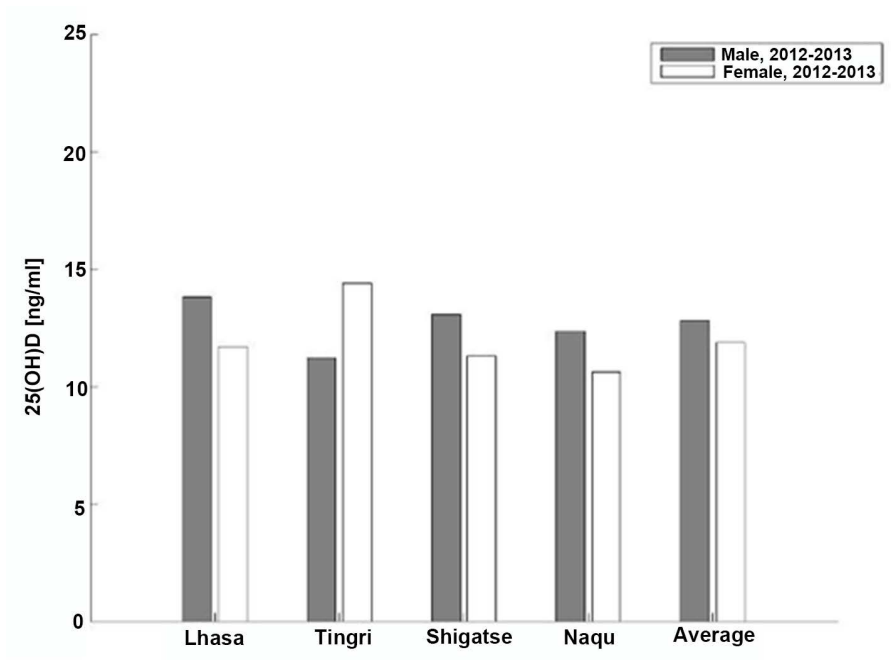

Figure 6. The serum 25(OH)D level in male and female during 2012 and 2013.

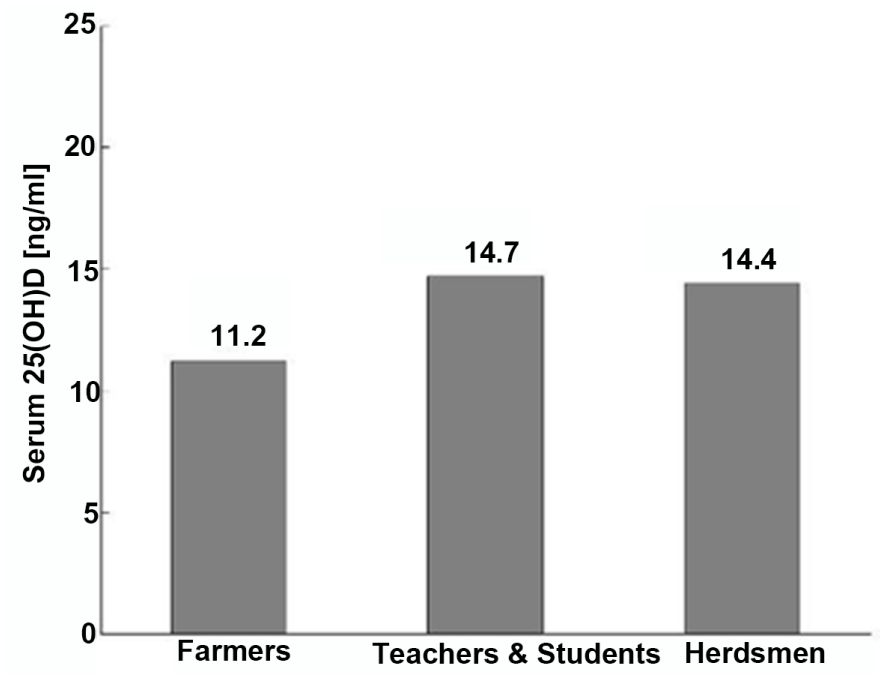

Figure 7. Average of $25(\mathrm{OH}) \mathrm{D}$ levels of different occupations during 2012 and 2013.

is $70 \mathrm{~W} / \mathrm{m}^{2}$. Moreover, annual duration of sunshine is about 3000 hours, an average of 9 hours a day in Tibet. But to our surprise, the average of 25(OH)D value for residents in Tibet is not in the adequate range, on the contrary, it's in severely low level (Figure 1 and Figure 2). Moreover, it was found that increasing with the years from 2007 to 2013, the level of 25(OH)D in Tibetans was decreased obviously (Figure 3). There are several explanations for this phenomenon.

1) Diet and sun exposure is the only two ways to supplement vitamin D. Diet contributes between $10 \%$ and $20 \%$ to $25(\mathrm{OH}) \mathrm{D}$ levels [21]. Recommendations for human intake of vitamin $\mathrm{D}$ have been given in different countries. American Endocrine Society suggested each adult should intake 600 - $1000 \mathrm{IU}(15-25 \mu \mathrm{g})$ vitamin D per day. It is necessary to have foods that contain high levels of vitamin D, such as fatty fish, liver, egg. However, in the present study, the food eaten 
by volunteers (mainly are Tibetans) consists of samba, wheat, yak yoghourt, yak meat and moderate amounts of vegetables. All these food sources are poor in vitamin D.

2) The major natural source of the vitamin is synthesis in the skin through a chemical reaction that is dependent on sun exposure. Although the UV radiation is high in Tibet, traditionally residents avoid sun exposure, in particular women. In China, since women consider white skin as a symbol of beauty, their outdoor activities are reduced. More and more people use parasol at all times for avoiding sun exposure, almost no skin was exposed in the sunshine. Therefore, our data revealed that the serum $25(\mathrm{OH}) \mathrm{D}$ level was lower in female than in male (Figure 6) and decreases from 2007 to 2013 (Figure 7).

3) The low winter temperature in Tibet (typically, the winter daily averaged temperature in Tibet is around $-5^{\circ} \mathrm{C}$, even much lower in many places) leads to less outdoor activities, so the decrease of serum 25(OH)D level is expected.

4) High incidence of altitude diseases (such as cataracts, melanoma) caused by solar radiation makes people cautious to solar radiation, which can damage their health.

There is a general lack of common knowledge for Tibetans concerning the importance of solar radiation and vitamin $\mathrm{D}$ synthesis.

The human serum 25(OH)D level is influenced by their occupation and work environment (Figure 7). Unexpectedly it was found that the serum $25(\mathrm{OH}) \mathrm{D}$ level of teachers and students was slightly higher than farmers. It is no clear explanation for this finding. But, because farmers have dark skin, it may take much more time to synthesize same amount of vitamin D in dark-skinned people, so that dermal synthesis from sunlight is hindered.

\section{Conclusion}

The solar UV radiation in Tibet is highly intensive, which can bring both favorable and unfavorable factors to human health. The most important thing is to let people know: 1) how to expose self correctly to the sun; 2) how to realize the importance of vitamin D synthesis from sunlight; 3) how to have a rational diet with adequate amount of vitamin $\mathrm{D}$. It is also important to continuously measure vitamin D level of Tibetans for further monitoring and improving the status of vitamin $\mathrm{D}$ and health in Tibet.

\section{Acknowledgements}

The present work was supported by the Mt. Everest Scholar Training Program (Norsang Gelsor and Tsoja Wangmu) of Tibet University and the Network for University Cooperation Tibet, Norway. We thank Vladimir Iani for comments both in science and language.

\section{References}

[1] Holick, M.F. (2006) High Prevalence of Vitamin D Inadequacy and Implications for Health. Mayo Clinic Proceedings, 81, 353. https://doi.org/10.4065/81.3.353 
[2] Armin and Zittermann (2003) Vitamin D in Preventive Medicine: Are We Ignoring the Evidence? British Journal of Nutrition, 89, 552-572.

[3] Wolf, G. (2004) The Discovery of Vitamin D: The Contribution of Adolf Windaus. Journal of Nutrition, 134, 1299-302.

[4] Grant, W.B. and Holick, M.F. (2005) Benefits and Requirements of Vitamin D for Optimal Health: A Review. Alternative Medicine Review. A Journal of Clinical Therapeutic, 10, 94.

[5] Bolland, M.J., Grey, A., Gamble, G.D., Reid, I.R., Bolland, M.J., Grey, A., Gamble, G.D., et al. (2014) The Effect of Vitamin D Supplementation on Skeletal, Vascular, or Cancer Outcomes: A Trial Sequential Meta-Analysis. The Lancet Diabetes \& Endocrinology, 2, 307-320.

[6] Byers, T. (2010) Anticancer Vitamins du Jour-The ABCED's so Far. American Journal of Epidemiology, 172, 1. https://doi.org/10.1093/aje/kwq112

[7] Moan, J., Porojnicu, A.C., Robsahm, T.E., Dahlback, A., Juzeniene, A., Tretli, S., et al. (2005) Solar Radiation, Vitamin D and Survival Rate of Colon Cancer in Norway. Journal of Photochemistry \& Photobiology B Biology, 78, 189-193. https://doi.org/10.1016/j.jphotobiol.2004.11.004

[8] Porojnicu, A.C., Robsahm, T.E., Ree, A.H. and Moan, J. (2005) Season of Diagnosis Is a Prognostic Factor in Hodgkin's Lymphoma: A Possible Role of Sun-Induced Vitamin D. British Journal of Cancer, 93, 571-574. https://doi.org/10.1038/sj.bjc.6602722

[9] Hewison, M. (2011) Vitamin D and Innate and Adaptive Immunity. Vitamins \& Hormones, 86, 23-62. https://doi.org/10.1016/B978-0-12-386960-9.00002-2

[10] Bolland, M.J., Grey, A., Gamble, G.D. and Reid, I.R. (2014) Vitamin D Supplementation and Falls: A Trial Sequential Meta-Analysis. The Lancet Diabetes \& Endocrinology, 2, 573-580. https://doi.org/10.1016/S2213-8587(14)70068-3

[11] Wagner, C.L., et al. (2012) Vitamin D and Its Role During Pregnancy in Attaining Optimal Health of Mother and Fetus. Nutrients, 4, 208-230. https://doi.org/10.3390/nu4030208

[12] Forman, J.P., Scott, J.B., Ng, K., Drake, B.F., Suarez, E.G., Hayden, D.L., et al. (2013) Effect of Vitamin D Supplementation on Blood Pressure in African-Americans. Hypertension, 61, 779. https://doi.org/10.1161/HYPERTENSIONAHA.111.00659

[13] (2013) Vitamin D Linked to Lower Rates of Tooth Decay. Clinical Dentistry.

[14] Johnson, K. and Sattari, M. (2015) Vitamin D Deficiency and Fatigue: An Unusual Presentation. SpringerPlus, 4, 1-4. https://doi.org/10.1186/s40064-015-1376-X

[15] Mokta, J., Mokta, K., Ranjan, A., Gupta, R. and Garg, M. (2016) Vitamin D Deficiency Presenting as Fatigue. Journal of the Association of Physicians of India, 64, 105.

[16] Shaffer, J.A., Edmondson, D., Wasson, L.T., Falzon, L., Homma, K., Ezeokoli, N., et al. (2014) Vitamin D Supplementation for Depressive Symptoms: A Systematic Review and Meta-Analysis of Randomized Controlled Trials. Psychosomatic Medicine, 76, 190-196. https://doi.org/10.1097/PSY.0000000000000044

[17] Shaikh, M.N., Malapati, B.R., Gokani, R., Patel, B. and Chatriwala, M. (2016) Serum Magnesium and Vitamin D Levels as Indicators of Asthma Severity. Pulmonary Medicine, 2016, Article ID: 1643717. https://doi.org/10.1155/2016/1643717

[18] Crissey, S.D., Ange, K.D., Jacobsen, K.L., Slifka, K.A., Bowen, P.E., Stacewiczsapuntzakis, M., et al. (2003) Serum Concentrations of Lipids, Vitamin D Metabolites, Retinol, Retinyl Esters, Tocopherols and Selected Carotenoids in 
Twelve Captive Wild Felid Species at Four Zoos. Journal of Nutrition, 133, 160-166.

[19] Norsang, G., Ma, L., Dahlback, A., Zhuoma, C., Tsoja, W., Porojnicu, A., et al. (2009) The Vitamin D Status among Tibetans. Photochemistry \& Photobiology, 85, 1028. https://doi.org/10.1111/j.1751-1097.2009.00552.x

[20] Rubin, A.L. (2011) Vitamin D for Dummies. Wiley Publishing Press, Hoboken.

[21] Christakos, S. and De Luca, H.F. (2011) Mini-Review: Vitamin D: Is There a Role in Extra-Skeletal Health? Endocrinology, 152, 2930-2936.

https://doi.org/10.1210/en.2011-0243 